\title{
Can Clinical Findings Prevent Negative Laparotomy in Parasitosis Mimicking Acute Appendicitis?
}

\author{
Musa Zorlu, ${ }^{1}$ İbrahim Tayfun Şahiner, ${ }^{1}$ Ahmet Çınar Yastı, ${ }^{1,2}$ Ethem Zobacı, ${ }^{3}$ \\ Ramazan Kocabaş, ${ }^{4}$ Abdullah Fahri Şahin, ${ }^{5}$ Faruk Coşkun, ${ }^{2}$ and Mete Dolapçı ${ }^{1}$ \\ ${ }^{1}$ Hitit University Medical School, Department of Surgery, 19030 Corum, Turkey \\ ${ }^{2}$ Numune Education and Research Hospital, Department of Surgery, Ankara, Turkey \\ ${ }^{3}$ Education and Research Hospital, Corum, Turkey \\ ${ }^{4}$ Hitit University Medical School, Department of Biochemistry, 19030 Corum, Turkey \\ ${ }^{5}$ Hitit University Medical School, Department of Pathology, 19030 Corum, Turkey
}

Correspondence should be addressed to İbrahim Tayfun Șahiner; tayfunsahiner@gmail.com

Received 31 January 2016; Accepted 7 April 2016

Academic Editor: Borna Relja

Copyright (C) 2016 Musa Zorlu et al. This is an open access article distributed under the Creative Commons Attribution License, which permits unrestricted use, distribution, and reproduction in any medium, provided the original work is properly cited.

\begin{abstract}
Objectives. Rates of negative laparotomy (NL) for acute appendicitis have been reported as 15\% and parasitosis contributed to $2 \%$. This study was planned to reduce the rates of NL by preoperative determination of parasitosis. Methods. In retrospective examination of 2730 appendectomy specimens in Hitit University Department of General Surgery between 2008 and 2012, 55 patients were determined with parasitosis and compared with 102 age-matched randomly selected patients with lymphoid hyperplasia. Results. The parasite group comprised $63.6 \%$ females with a mean age of 15.1 years. The number of patients in the parasitosis group increased from city centre to rural areas of towns and villages $(p<0.001)$. While a lower rate of sonographic findings was found in the parasitosis group, the findings of inflammation in the histopathological evaluation were significantly low $(p=0.014, p=0.0011$, resp.). A significant difference was determined between groups in respect of the eosinophil and haematocrit values. In the differentiation of patients with parasites, eosinophil of $>2.2 \%$ was determined as a diagnostic value. Conclusion. It is important to determine parasitosis to prevent NL. When acute appendicitis is considered for young patients living in rural areas, the observation of high eosinophil together with negative sonographic findings should bring Enterobius vermicularis parasitosis to mind and thereby should prevent NL.
\end{abstract}

\section{Introduction}

Acute appendicitis is the pathology requiring the most frequent emergency surgery in General Surgery and appendectomy is the most common surgical procedure worldwide [1]. In the general population, the lifetime risk of developing appendicitis is $8.6 \%$ for males and $6.7 \%$ for females. In contrast, the rates of appendectomy performed during laparotomy for an initial diagnosis of acute appendicitis (AA) are $12 \%$ for males and $25 \%$ for females [2]. The reason for these higher than expected rates of appendectomy is that appendectomies are performed during negative laparotomies on patients admitted for surgery because of a clinical table resembling acute appendicitis. The rate of negative appendectomy has been reported as mean $15 \%$ and of these $2 \%$ comprise appendectomies associated with parasitosis [3]. More than the experience of unnecessary surgical trauma for patients, negative laparotomies may cause more serious problems in the future such as ileus associated intra-abdominal adhesions and female infertility due to tubal contractions.

Enterobius vermicularis (EV) and Ascaris lumbricoides (AL) of the nematode family cause perianal itching, loss of appetite, abdominal pain, diarrhoea, weight loss, nasal itching, and dental irritation in patients [4]. Diagnosis is made from the observation of parasites and/or parasite eggs in faecal examination or using the method of applying a cellophane band to the perianal region at night. Treatment is provided with oral mebendazole or pyrantel pamoate. In regions where parasites are often seen, community education programs are applied for the prevention of parasites. In 
TABLE 1: Correlations between patient age and parasitosis.

\begin{tabular}{|c|c|c|c|c|c|}
\hline & \multicolumn{5}{|c|}{ Age (years) } \\
\hline & Mean & Standard deviation & Median & Minimum & Maximum \\
\hline Parasite group & 15.1 & 9.5 & 12.0 & 3.0 & 50.0 \\
\hline \multirow[t]{2}{*}{ Lymphoid group } & 15.9 & 9.8 & 14.0 & 3.0 & 51.0 \\
\hline & \multicolumn{2}{|c|}{$\begin{array}{c}\quad p=0.651 \\
\text { (Independent } t \text {-test) }\end{array}$} & \multicolumn{3}{|c|}{$\begin{array}{c}p=0.579 \\
\text { (Mann-Whitney } U \text { test) }\end{array}$} \\
\hline
\end{tabular}

addition, in parasitosis endemic regions, the consideration of parasitosis in the etiology of patients with an initial diagnosis of AA could reduce the rates of negative laparotomy.

In this study, we aim to investigate the predictability of parasite etiopathogenesis with tests applied in the preoperative period to patients with an initial diagnosis of AA and by planning medical treatment, thereby preventing negative laparotomy.

\section{Material and Method}

A retrospective examination was made of 2730 patients who underwent appendectomy in Hitit University Department of General Surgery between 01 January 2008 and 31 December 2012. Based on the final histopathological evaluation, the patients were classified according to the etiology. The study group was formed of 55 patients who were determined with parasitosis in the pathology report. As a comparative group, 102 age-matched patients with pathology reported as lymphoid hyperplasia were selected by a random sampling method.

The demographic information of the two groups was recorded as gender, age, and place of residence (city centre, town, and village). The results were recorded of the full blood count on first presentation at the Emergency Department (basophil, eosinophil, lymphocyte, number and percentage of monocytes and neutrophils, haematocrit, haemoglobin, mean corpuscular volume, mean corpuscular haemoglobin concentration, mean thrombocyte volume, platelet, red cell number, reticulocyte distribution width, and white cell number values). For each patient it was recorded whether or not the ultrasonographic findings were consistent with appendicitis.

In the histological evaluation, the preparations of patients diagnosed with parasitosis were reevaluated. Parasites were classified according to observation. In addition, results were recorded of the evaluation of the presence of infection findings in the appendix lumen.

In the statistical analysis, the normal distribution analyses were applied with the Kolmogorov-Smirnov test. In the comparison of categorical variables, the Chi-square test was used, and for intergroup comparison of continuous data, the Mann-Whitney $U$ test was used. ROC analysis was applied for the determination of diagnostic values. The results were given as number and percentage for categorical data and as median (95\% CI) for continuous data. A value of $p<0.05$ was accepted as statistically significant.

\section{Results}

During the study period, 2730 patients underwent surgery for AA. These patients comprised 1474 (53\%) females and 1256 (47\%) males. In the pathology examination, 55 (2\%) patients were reported as having parasitosis. In the histopathological evaluation of the parasitosis group, parasite structures containing eggs were observed in the appendix lumen on sections prepared with haematoxylin-eosin. The parasite type was determined (Enterobius vermicularis, Ascaris lumbricoides).

In the examination of the age distribution of the patients, the mean age of the whole group was found to be $15.6 \pm 9.7$ years (range, 3-51 years) and the median was 13 years (11$15,95 \% \mathrm{CI}$ ). The age of the parasite group was determined as $15.1 \pm 9.5$ years and the lymphoid group $15.9 \pm 9.8$ years and the distribution was homogenous between the groups (Table 1).

In respect of gender distribution, the parasite group of 55 patients comprised 20 (36.4\%) males and 35 (63.6\%) females and the lymphoid group $36(35.3 \%)$ males and $66(64.7 \%)$ females. The gender distribution between the groups was homogenous (Table 2).

In the examination of the place of residence of the patients, while it was determined that an increasing number of patients in the parasite group lived in rural areas of a village or town, a reduction in this direction was observed in the lymphoid group. Distribution of cases in the parasite group according to the place of residence was evaluated with the Chi-square test and the increase was determined to be statistically significant $(p<0.001)$ (Table 3$)$.

From the results of the pathological evaluation, Enterobius vermicularis was determined in 54 (98.2\%) cases and Ascaris lumbricoides in 1 case (1.8\%).

The presence of parasites was correlated with the ultrasonography results of the patients (Table 2). In the parasitosis group, a lower rate of USG findings in favour of AA was found to be statistically significant compared to the lymphoid group $(p=0.014)$.

When the appendectomy specimens were evaluated for the presence of findings of inflammation, while there were no inflammation findings in the majority of the parasitosis group, they were observed in the majority of the lymphoid group. The difference between the two groups in the evaluation of findings related to inflammation on the appendix was tested with the Pearson Chi-square test and was found to be statistically significant ( $p=0.0011)$ (Table 2 ).

As a result of the evaluations according to the full blood count parameters of the groups, a statistically significant 
TABLE 2: Correlations between the parasite and lymphoid groups regarding patient gender, USG evaluation, and postoperative histopathological findings.

\begin{tabular}{|c|c|c|c|c|c|}
\hline \multirow{2}{*}{ Parameter } & \multicolumn{2}{|c|}{ Parasite group } & \multicolumn{2}{|c|}{ Lymphoid group } & \multirow{2}{*}{$p$} \\
\hline & $N$ & $\%$ & $N$ & $\%$ & \\
\hline \multicolumn{6}{|l|}{ Gender } \\
\hline Female & 35 & 63.6 & 66 & 64.7 & \multirow{2}{*}{$p=0.967$} \\
\hline Male & 20 & 36.4 & 36 & 35.3 & \\
\hline \multicolumn{6}{|l|}{ Diagnostic finding } \\
\hline USG (-) & 21 & 70.0 & 19 & 38.8 & \multirow{2}{*}{$p=0.014$} \\
\hline USG (+) & 9 & 30.0 & 30 & 61.2 & \\
\hline \multicolumn{6}{|c|}{ Histopathological examination } \\
\hline Inflammation $(-)$ & 39 & 70.9 & 43 & 42.2 & \multirow{2}{*}{$p=0.0011$} \\
\hline Inflammation $(+)$ & 16 & 29.1 & 59 & 57.8 & \\
\hline
\end{tabular}

TABLE 3: Correlations between place of residence and the presence of parasites.

\begin{tabular}{lcccccc}
\hline & \multicolumn{2}{c}{ City centre } & \multicolumn{2}{c}{ Town } & \multicolumn{2}{c}{ Village } \\
& $N$ & $\%$ & $N$ & $\%$ & $N$ & $\%$ \\
\hline Parasite group & 8 & 14.5 & 14 & 25.4 & 33 & 60 \\
Lymphoid group & 85 & 83.3 & 13 & 12.7 & 4 & 3.9 \\
\hline
\end{tabular}

$p<0.001$.

difference was observed between the eosinophil count, eosinophil percentage, and haematocrit values (Table 4). In the differentiation of the parasitosis patients, the diagnostic value of the eosinophil percentage was evaluated with ROC analysis. Eosinophil percentage of $>2.2$ (even in the normal range) was determined as a diagnostic value with $46 \%$ sensitivity and $80.8 \%$ specificity $(\mathrm{AUC}=0.652, \mathrm{AUC}=$ area under the ROC curve) (Figure 1).

\section{Discussion}

The rates of appendectomy performed with an initial diagnosis of AA are far higher than the lifetime risk of development of appendicitis [2]. While the rate of negative laparotomy is as high as $15 \%, 2 \%$ of that total comprises appendectomies associated with parasitosis [3]. Negative laparotomy causes various risks later in life such as intra-abdominal adhesions, tubal adhesions, and infertility.

Enterobius vermicularis (EV) of the nematode family is known as pinworm and is one of the agents of frequently seen nematode infections. Approximately 200 million people worldwide are reported to be infected. In a study in the USA in 2000, it was reported to have been found in 42 million people in the country. Although there are no regularly collected data in studies, it has been reported to be common in Turkey [5].

The life-cycle of EV in humans starts with the autospread of eggs in the perianal skin reaching the mouth from under the fingernails. Person-to-person transfer is rare although it can occur from dirty toilets and places of poor hygiene. A very small proportion may be located in the respiratory

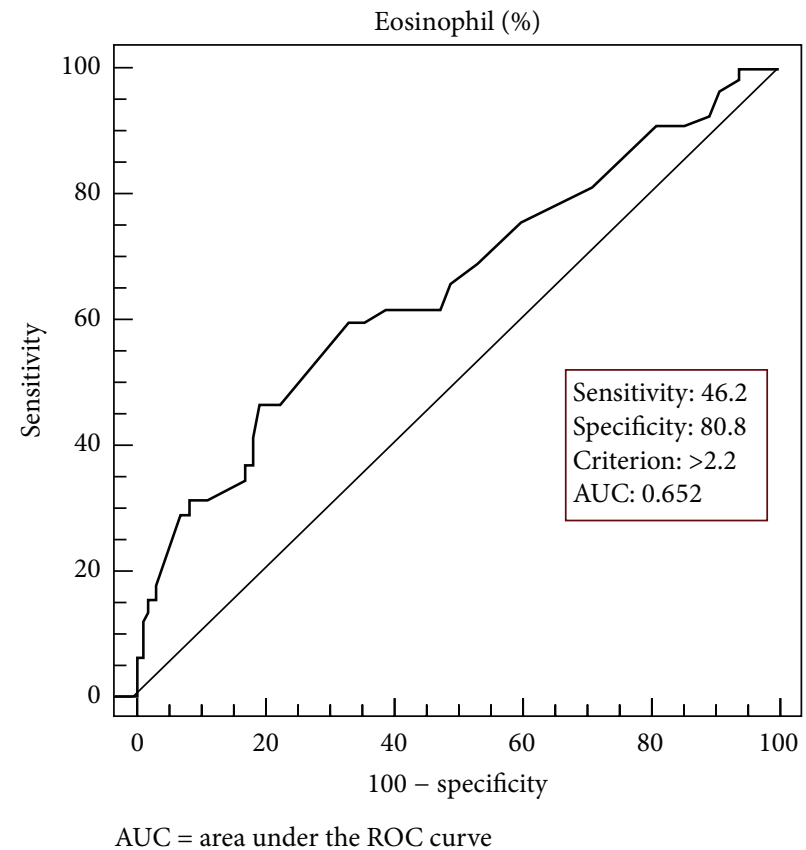

FIGURE 1: Sensitivity and specificity of eosinophil percentage in the determination of the presence of parasitosis.

system with inhalation. Eggs ingested orally open in the small intestine and parasites emerge from the eggs. The adult forms settle in the ascendant colon, particularly in the cecum, the appendix, and the terminal ileum area. This interval lasts approximately one month. The lifespan of the adult forms is 2 months. After fertilisation, the males die and the females lay eggs in the perianal area at night. At this time, perianal itching occurs in patients. The newly emerging larvae in the edges of the anal canal create the disease within the rectum by reentering with retroinfection or migration [6]. Patients may present with complaints and findings such as perianal itching, macroscopic or microscopic blood in the faeces, loss of appetite, abdominal pain, diarrhoea, weight loss, nasal itching, dental irritation, dizziness, buzzing in the ears, anaemia, and eosinophilia [4]. 
TABLE 4: Correlations of the full blood count parameters of the parasite and lymphoid groups.

\begin{tabular}{|c|c|c|c|c|c|c|}
\hline \multirow{2}{*}{ Parameter } & & \multicolumn{2}{|c|}{ Parasite group } & \multicolumn{2}{|c|}{ Lymphoid group } & \multirow{2}{*}{$p$} \\
\hline & & Median & $95 \%$ CI & Median & $95 \%$ CI & \\
\hline WBC & $10^{9} / \mathrm{L}$ & 11.2 & $9.529-14.160$ & 13 & $11.263-13.800$ & 0.628 \\
\hline \multirow{2}{*}{ Eosinophil } & $10^{9} / \mathrm{L}$ & 0.24 & $0.200-0.305$ & 0.18 & $0.130-0.200$ & $0.005^{*}$ \\
\hline & $\%$ & 2 & $1.400-2.807$ & 1.3 & $1.127-1.500$ & $0.002^{*}$ \\
\hline \multirow{2}{*}{ Neutrophil } & $10^{9} / \mathrm{L}$ & 7.675 & $6.323-9.489$ & 9.1 & $7.653-10.455$ & 0.336 \\
\hline & $\%$ & 74.05 & $65.140-78.300$ & 73.9 & $70.317-77.277$ & 0.505 \\
\hline \multirow{2}{*}{ Lymphocyte } & $10^{9} / \mathrm{L}$ & 2.13 & $1.773-2.497$ & 2.225 & $1.900-2.560$ & 0.410 \\
\hline & $\%$ & 18.1 & $13.099-25.874$ & 19.3 & $16.901-21.175$ & 0.873 \\
\hline \multirow{2}{*}{ Monocyte } & $10^{9} / \mathrm{L}$ & 0.575 & $0.480-0.700$ & 0.6 & $0.550-0.648$ & 0.629 \\
\hline & $\%$ & 5.5 & $4.565-6.400$ & 5 & $4.535-5.783$ & 0.512 \\
\hline \multirow{2}{*}{ Basophil } & $10^{9} / \mathrm{L}$ & 0.035 & $0.020-0.050$ & 0.04 & $0.030-0.060$ & 0.544 \\
\hline & $\%$ & 0.4 & $0.200-0.500$ & 0.4 & $0.200-0.500$ & 0.678 \\
\hline Haemoglobin & $\mathrm{g} / \mathrm{dL}$ & 12.7 & $12.200-13.071$ & 13.2 & $12.900-13.500$ & 0.056 \\
\hline Haematocrit & $\%$ & 37.3 & $36.105-38.736$ & 39.15 & $38.400-40.237$ & $0.035^{*}$ \\
\hline $\mathrm{MCH}$ & pg & 27.5 & $26.853-28.024$ & 27.2 & $26.863-27.737$ & 0.615 \\
\hline $\mathrm{MCHC}$ & $\mathrm{g} / \mathrm{dL}$ & 33.2 & $32.900-33.600$ & 33.2 & $33.000-33.537$ & 0.780 \\
\hline $\mathrm{MCV}$ & $\mathrm{fL}$ & 82 & $80.764-83.000$ & 82 & $80.250-84.000$ & 0.416 \\
\hline $\mathrm{RBC}$ & $10^{12} / \mathrm{L}$ & 4.66 & $4.565-4.854$ & 4.835 & $4.701-4.900$ & 0.347 \\
\hline RDW & $\%$ & 13.4 & $13.100-13.900$ & 13.2 & $13.100-13.300$ & 0.062 \\
\hline PLT & $10^{9} / \mathrm{L}$ & 308 & 273-321 & 277 & 268-301 & 0.522 \\
\hline PCT & $\%$ & 0.27 & $0.230-0.306$ & 0.26 & $0.240-0.301$ & 0.647 \\
\hline MPV & $\mathrm{fL}$ & 8.7 & $8.300-9.271$ & 9 & $8.500-9.437$ & 0.513 \\
\hline
\end{tabular}

WBC: white blood cell, MCH: mean corpuscular haemoglobin, MCHC: mean corpuscular haemoglobin concentration, MCV: mean corpuscular volume, RBC: red blood cell, RDW: red blood cell distribution width, PLT: platelet, PCT: plateletcrit, and MPV: mean platelet volume.

Diagnosis is made with the visualisation of adult EV or eggs in microscopic evaluation of the faeces. A cellophane band applied to the perianal area throughout the night is also useful in diagnosis. In the method, the EV or eggs emerging out of the anal area at night stick to the band and thus diagnosis can be made [3].

The pathogenesis of EV in the development of appendicitis has not yet been fully clarified. EV is not an invasive pathogen in the gastrointestinal system lumen. However, by creating an obstruction in the appendix lumen, the adult forms can cause ischaemia and appendicitis with the progression of this table to perforation and peritonitis. As the majority of cases have no findings of inflammation, the hypothesis of "appendical syndrome" has been created. This syndrome is referred to as appendical colic. The hypothesis is characterised by intermittent chronic, right lower quadrant and pelvic pain which develops associated with obstruction of the appendix lumen $[3,6]$. In the current study, no findings of inflammation were encountered in a significant proportion $(70.9 \%)$ of the patients in the histopathological evaluation which is parallel to the literature [3]. Moreover, inflammation was seen in the surgical material of $29.1 \%$ of the patients with real acute appendicitis and this rate has been reported in literature at 13-37\% [1]. The results of the current study, revealing a similar table to appendicitis of EV in the appendix without inflammation, support the appendical syndrome hypothesis in literature.
In medical treatment, antihelmintic agents are used, primarily single-dose $100 \mathrm{mg}$ oral mebendazole or $11 \mathrm{mg} / \mathrm{kg}$ pyrantel pamoate. Although $90 \%$ eradication is achieved with this treatment, reinfestation is often seen. For long-term eradication, the medical treatment must be repeated after 2 weeks. It is necessary to achieve eradication from the whole family. However, before this, EV eggs must be eradicated from all the contaminated areas by cleaning because the eggs can remain alive in these areas for 2-3 weeks [6].

Medical treatment must be started in patients determined with EV in the pathology report after appendectomy. Appendectomy can remove the symptom of abdominal pain but cannot remove the primary cause of parasitosis [7].

$\mathrm{EV}$ in the appendix lumen was first described by Fabrius in 1634 [8]. In studies conducted on various paediatric and adult age groups, appendicitis associated with EV has been reported at rates of $2-4.1 \%[4,7,9]$. The global reported prevalence of EV infestation in patients with symptoms of appendicitis has been reported to range from 0.2 to $4.1 \%[1,3]$. However, parasitosis may not be the agent of appendicitis in every carrier of EV.

Frequent rates of EV have been reported to be observed in childhood between the ages of 5 and 14 years [6]. In the current study, the mean age of the parasite group was found to be $15.1 \pm 9.5$ years with a median of 12 years. Although the age difference between the groups was not significant in showing the presence of parasitosis, the median age of the lymphoid 
group was seen to be 14 years. The young age of the patients in both groups will make a contribution to the risk of the development of intra-abdominal complications secondary to laparotomy which may occur later in life.

Ultrasonography (USG) and computerised tomography (CT) are valuable in the diagnosis of appendicitis with sensitivity of $95 \%$ and $96 \%$, respectively. Negative predictive value has been reported as $99 \%$ [7]. In the patients with appendix parasitosis in the current study, findings of AA were observed in $70 \%$. High rates of negative predictive value of ultrasonography were seen in the current series and a statistically significant difference was found in comparison with the USG results of the lymphoid group $(p=0.014)$. The reason for having no sonographic difference in the anatomic structure of the appendix is that there was no appendicular inflammation in the etiopathogenesis of the event, which supports the appendiceal colic hypothesis. In parallel, in the histopathological evaluation of study and control group specimens, it was reported that inflammation was not observed in $70.9 \%$ of the parasitosis group $(p=0.0011)$. The histopathological findings were found to support the ultrasound results.

In the full blood count of the patients, the median value of the white cell count was found to be $11.9 \times 10^{9} / \mathrm{L}$ (normal: $8-12 \times 10^{9}$ ). Even both were within normal limits, and the median value of the eosinophil count in the parasitosis group $\left(0.24 \times 10^{9} / \mathrm{L}\right)$ was found to be higher than the lymphoid group. The eosinophil rates in the parasitosis and lymphoid groups were found to be $2 \%$ and $1.3 \%$, respectively, and both were also in normal range. However, in comparison with the lymphoid group, both the eosinophil count and the eosinophil percentage of the parasitosis group were found to be significantly high. In another study, although the increased eosinophil value was suggested to be used in differential diagnosis, no numerical value was defined in their series [7]. In the current study, a value of eosinophil over $2.2 \%$, even in the normal range, indicated the presence of parasitosis with $46.2 \%$ sensitivity and $80.8 \%$ specificity.

Limitations of our study are firstly being a retrospective study, and secondly, regarding the lack of availability of all data digitally, study group was compared to the randomly selected group of the patients.

\section{Conclusion}

The results of the current study showed that, in geographic regions where parasitosis is often encountered, in the evaluation of paediatric patients who present with acute abdomen which suggests acute appendicitis in the differential diagnosis, parasitosis should be kept in mind. Particularly in places with a high incidence of regional parasites, in patients with higher eosinophil values and no findings of acute appendicitis on ultrasonography, parasitosis must be considered in the differential diagnosis to avoid a negative laparotomy.

\section{Disclosure}

Former affiliation of Faruk Coşkun is Hitit University Medical School, Department of Surgery, Corum, Turkey.

\section{Competing Interests}

No competing interests arose on behalf of any author.

\section{Acknowledgments}

The authors would like to thank Mrs. Caroline J. Walker for editing the language of this paper. All phases of the study were carried out at the Hitit University Medical School, Corum Education and Research Hospital, Corum, Turkey.

\section{References}

[1] S. Akbulut, M. Tas, N. Sogutcu et al., "Unusual histopathological findings in appendectomy specimens: a retrospective analysis and literature review," World Journal of Gastroenterology, vol. 17, no. 15, pp. 1961-1970, 2011.

[2] D. R. Flum and T. Koepsell, "The clinical and economic correlates of misdiagnosed appendicitis: nationwide analysis," Archives of Surgery, vol. 137, no. 7, pp. 799-804, 2002.

[3] Ö. Aydin, "Incidental parasitic infestations in surgically removed appendices: a retrospective analysis," Diagnostic Pathology, vol. 2, article 16, 2007.

[4] Ö. Engin, S. Calik, B. Calik, M. Yildirim, and G. Coskun, "Parasitic appendicitis from past to present in Turkey," Iranian Journal of Parasitology, vol. 5, no. 3, pp. 57-63, 2010.

[5] B. Isik, M. Yilmaz, N. Karadag et al., "Appendiceal enterobius vermicularis infestation in adults," International Surgery, vol. 92, no. 4, pp. 221-225, 2007.

[6] J. E. Carter, J. J. Nelson, and K. N. Mizell, "Abdominal pain in an 8-year-old male," Laboratory Medicine, vol. 38, no. 6, pp. 357360, 2007.

[7] E. Gialamas, T. Papavramidis, N. Michalopoulos et al., "Enterobius vermicularis: a rare cause of appendicitis," Türkiye Parazitolojii Dergisi, vol. 36, no. 1, pp. 37-40, 2012.

[8] G. F. Fry and J. G. Moore, "Enterobius vermicularis: 10,000year-old human infection," Science, vol. 166, no. 913, p. 1620, 1969.

[9] M. J. Arca, R. L. Gates, J. I. Groner, S. Hammond, and D. A. Caniano, "Clinical manifestations of appendiceal pinworms in children: an institutional experience and a review of the literature," Pediatric Surgery International, vol. 20, no. 5, pp. 372375, 2004. 


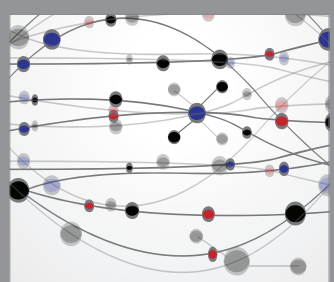

The Scientific World Journal
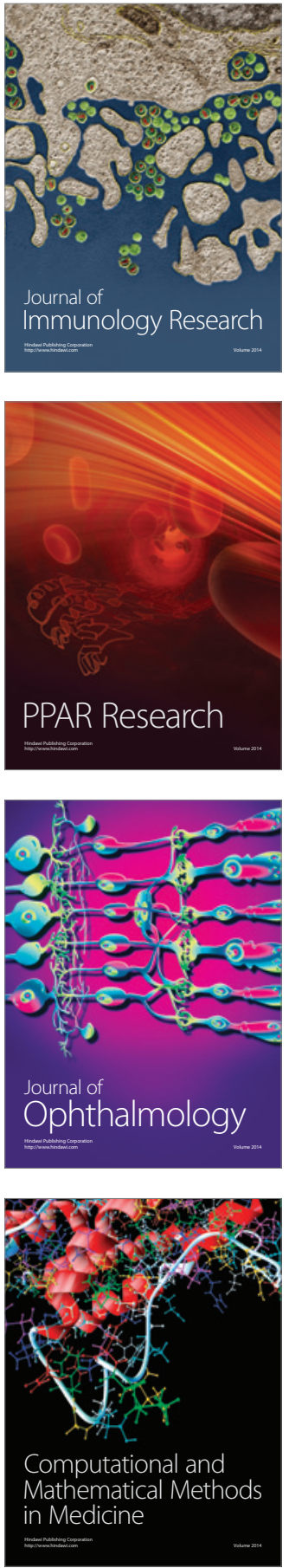

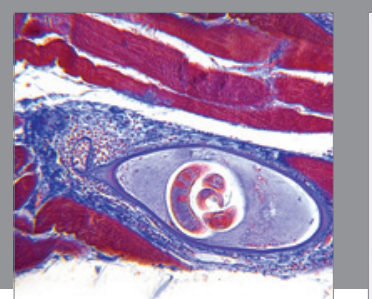

Gastroenterology Research and Practice

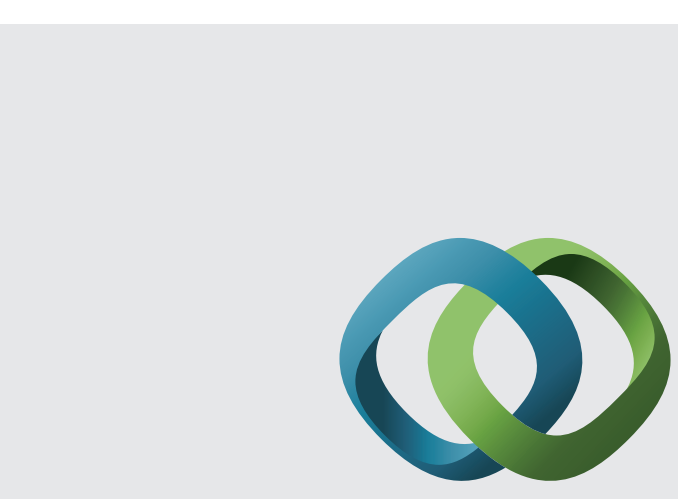

\section{Hindawi}

Submit your manuscripts at

http://www.hindawi.com
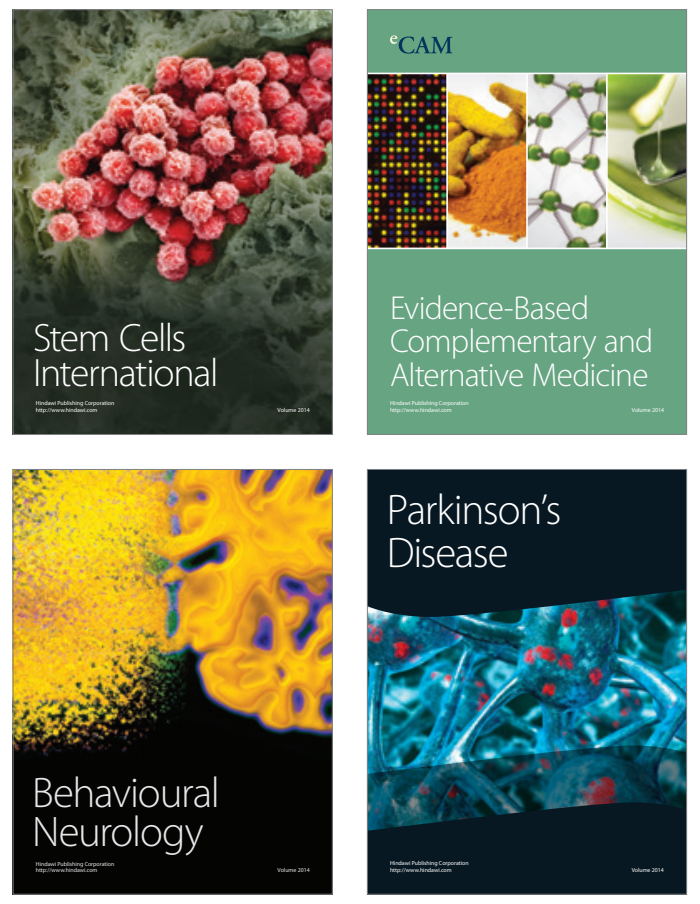
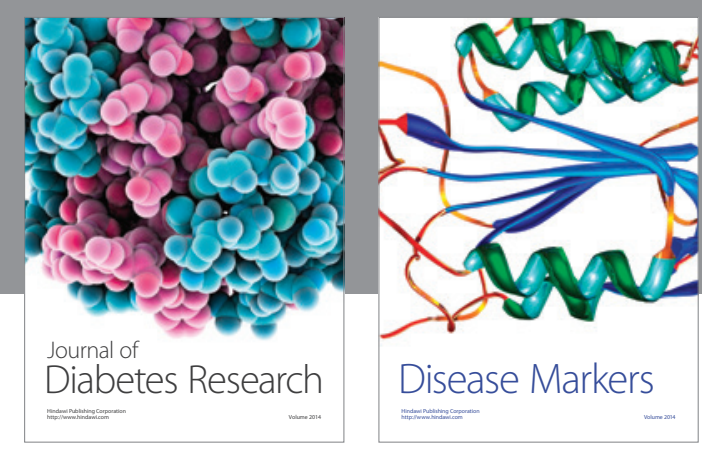

Disease Markers
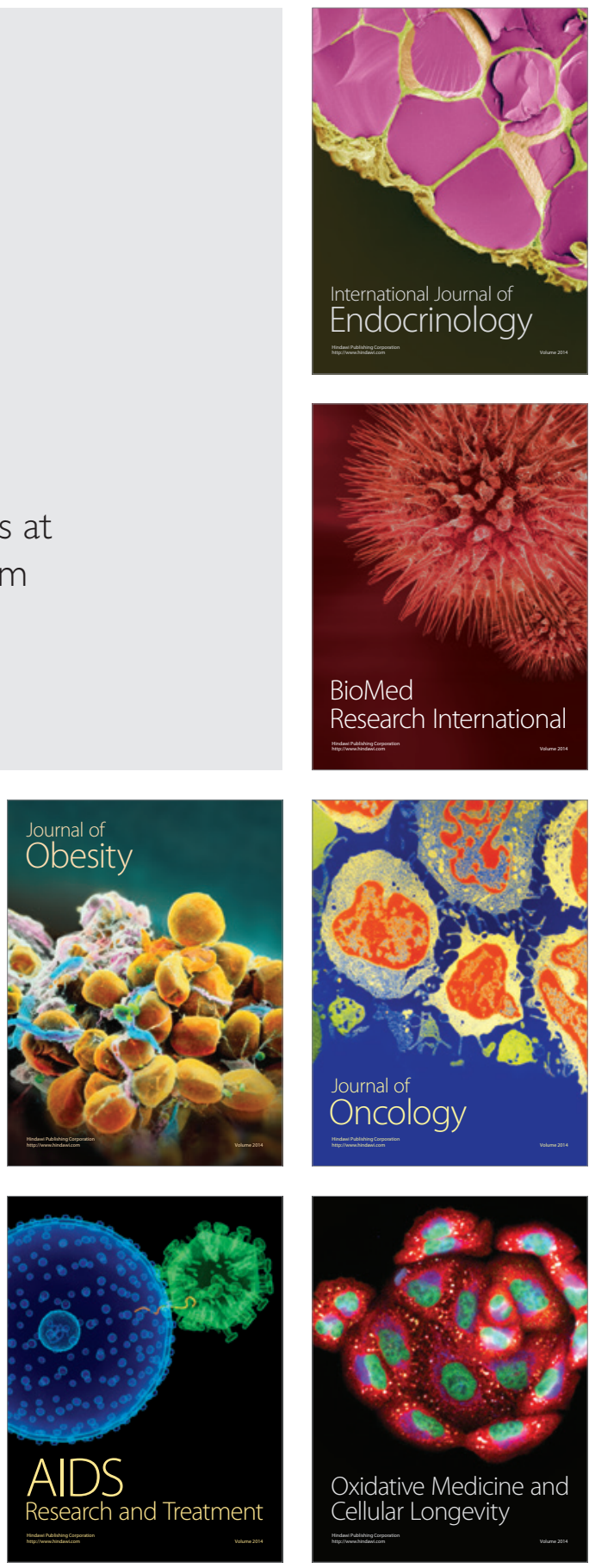